\title{
Investigation of Effects of Tool Geometry Parameters on Cutting Forces, Temperature and Tool Wear in Turning Using Finite Element Method and Taguchi's Technique
}

\author{
Le Hieu Giang, Mai Duc Dai, Pham Minh Duc \\ Faculty of Mechanical Engineering, University of Technology and Education, Hochiminh City, Vietnam
}

Email address:

ducpm@hcmute.edu.vn (P. M. Duc)

\section{To cite this article:}

Le Hieu Giang, Mai Duc Dai, Pham Minh Duc. Investigation of Effects of Tool Geometry Parameters on Cutting Forces, Temperature and Tool Wear in Turning Using Finite Element Method and Taguchi's Technique. International Journal of Mechanical Engineering and Applications. Vol. 4, No. 3, 2016, pp. 109-114. doi: 10.11648/j.ijmea.20160403.12

Received: April 25, 2016; Accepted: May 19, 2016; Published: June 6, 2016

\begin{abstract}
Turning is one of the most widely metal cutting methods. Machines, tool geometry and machining parameters are the main factors influencing machining quality and efficiency. So there is a lot of research on it. This paper studies on the influence of the geometrical parameters of the tool including: back rake angle (BR), side rake angle (SR) and side cutting-edge angle (SCEA) on cutting forces, temperature and tool wear in turning using FEM (by Deform 3D finite element simulation software) and Taguchi's technique (by Minitab16 statistical software) is used to design the experiment and to analyze output quality characteristics from simulation results. And the optimum tool geometry parameters are given.
\end{abstract}

Keywords: FEM, FEA, BR, SR, SCEA, Deform 3D, Taguchi Method, S/N Ratio

\section{Introduction}

Turning is a method of machining by cutting in which the workpiece carries out the main rotary motion while the tool performs the linear motion. The process is used for the external and internal turning of surfaces [1].

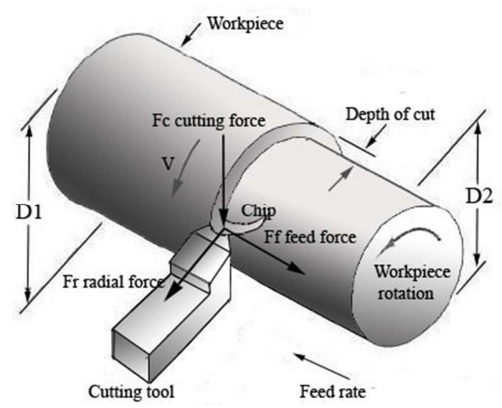

Fig. 1. Schematic diagram of turning operation and cutting forces.

The forces impacting on the cutting tool during machining process are named cutting forces. They influence the life of the tool, the machined work piece's dimensional accuracy and quality of the surface.
The heat generation is closely related to the plastic deformation and friction, we can specify three main sources of heat when cutting, plastic deformation by shearing in the primary shear zone (heat source Q1), plastic deformation by shearing and friction on the cutting face (heat source Q2), friction between chip and tool on the tool flank (heat source Q3) and heat is mostly dissipated by the discarded chip about $60 \sim 80 \%$ of the total heat (q1), the workpiece about $10 \sim 20 \%$ heat (q2) and the cutting tool about $\sim 10 \%$ heat (q3) [2]. The cutting temperature affects the life of the cutting tool, on the tool and work piece material properties.

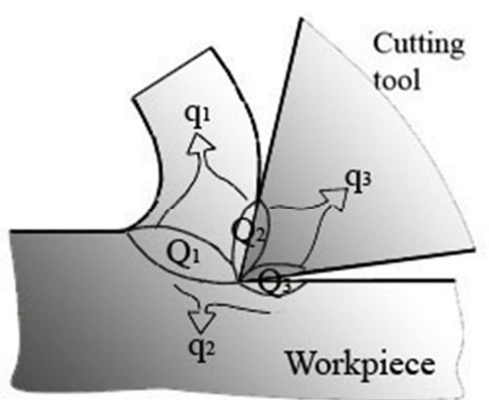

Fig. 2. The balance of heat generation and heat dissipation in the metal cutting process. 
The wear of tool influences the machined work piece's dimensional accuracy and quality of the surface.

Therefore, the main objective of this research is the study of the influence of the geometric parameters of the tool on the cutting forces, temperature and tool wear in turning to improve the tool geometry parameters. The input quality characteristics of simulation analysis are shown in the tables below.

The workpiece material used for the metal cutting simulation is AISI 1045 steel, a medium carbon, medium tensile steel. It has very good machinability, reasonable weldability. Typical engineering applications of AISI 1045 steel are as gears, shafts, axles, bolts, studs and machine parts.
Table 1. The tool geometry parameters and its levels.

\begin{tabular}{lllll}
\hline Tool geometry parameters & Level 1 & Level 2 & Level 3 & Level 4 \\
\hline SCEA $\left(^{\circ}\right)$ & 0 & 15 & 30 & 45 \\
$\mathrm{BR}\left({ }^{\circ}\right)$ & -5 & -7 & -9 & -11 \\
$\mathrm{SR}\left({ }^{\circ}\right)$ & -5 & -7 & -9 & -11 \\
\hline
\end{tabular}

Table 2. The machining parameters.

\begin{tabular}{lll}
\hline Cutting speed(m/min) & Feed rate(mm/rev) & Depth of $\operatorname{cut}(\mathbf{m m})$ \\
\hline 103.2 & 0.16 & 2 \\
\hline
\end{tabular}

Table 3. Mechanical and thermal properties of AISI 1045 carbon steel.

\begin{tabular}{|c|c|c|c|c|c|c|}
\hline $\begin{array}{l}\text { Density } \\
\left(\text { g.cm }{ }^{-3}\right)\end{array}$ & $\begin{array}{l}\text { Poisson } \\
\text { ratio }\end{array}$ & $\begin{array}{l}\text { Elasticity } \\
(\text { GPa })\end{array}$ & $\begin{array}{l}\text { Thermal conductivity } \\
\left(\mathbf{W} \cdot \mathrm{m}^{-10} \mathrm{~K}^{-1}\right)\end{array}$ & $\begin{array}{l}\text { Specific heat } \\
\left(\mathrm{J}_{\mathrm{kg}}^{-1} \cdot \mathrm{K}^{-1}\right)\end{array}$ & $\begin{array}{l}\text { Thermal expansion } \\
\left(\mu \mathrm{m} \cdot \mathrm{m}^{-1} \mathrm{~K}^{-1}\right)\end{array}$ & $\begin{array}{l}\text { Hardness } \\
\text { (HB) }\end{array}$ \\
\hline 7.87 & 0.29 & 212 & 41.7 & 450 & 11.9 & 170 \\
\hline
\end{tabular}

The material for cutting tool insert is uncoated cemented carbide, which has a good hot hardness, wear resistance and strength for metal cutting operations.

Table 4. Mechanical and thermal properties of tungsten carbide insert.

\begin{tabular}{llllll}
\hline $\begin{array}{l}\text { Density } \\
\left(\mathbf{g} . \mathbf{c m}^{-3}\right)\end{array}$ & $\begin{array}{l}\text { Poisson } \\
\text { ratio }\end{array}$ & $\begin{array}{l}\text { Elasticity } \\
(\mathbf{G P a})\end{array}$ & $\begin{array}{l}\text { Thermal conductivity } \\
\left(\mathbf{W} \cdot \mathbf{m}^{-1} \mathbf{K}^{-1}\right)\end{array}$ & $\begin{array}{l}\text { Specific heat } \\
\left(\mathbf{J}_{\mathbf{k g}} \mathbf{- 1} \cdot \mathbf{K}^{-1}\right)\end{array}$ & $\begin{array}{l}\text { Thermal expansion } \\
\left(\boldsymbol{\mu m} . \mathbf{m}^{-1} \circ \mathbf{C}^{-1}\right)\end{array}$ \\
\hline 15 & 0.25 & 650 & 59 & 15 & 5 \\
\hline
\end{tabular}

\section{Finite Element Method (FEM)}

In recent years, the finite element method (FEM) is the most popular method of simulation and finite element analysis (FEA) has become the main tool for simulating metal cutting processes. Because FEA requires less time and cost as well as it provides detailed results such as the cutting force, stress, strain, strain rate, tool wear and temperature of the metal cutting process. There are some popular finite element softwares for simulation of cutting process such as Ansys, Deform 3D, Abaqus, etc. In this paper, the FEM software Deform 3D with updated Lagrangian formulation combined with automatic remeshing techniques [3] is used to simulate turning process. In this approach, there is no need for a chip separation criterion, making it is highly effective in simulating metal cutting process [4]. The important factor in the metal cutting simulation is modelling the process properly in order to obtain true results. This software includes several key models as: the material constitutive model; tool wear model; friction model and thermal model.

And the most important one is the material constitutive model. The metal cutting process is the large strain, high strain rate and high temperature process. And Johnson-Cook material model (1) is favored as well in studies of problems like that.

$$
\bar{\sigma}=\left[\mathrm{A}+\mathrm{B}(\bar{\varepsilon})^{n}\right]\left[1+\mathrm{Cln}\left(\frac{\dot{\bar{\varepsilon}}}{\dot{\bar{\varepsilon}}_{o}}\right)\right]\left[1-\left(\frac{T-T_{o}}{T_{m}-T_{o}}\right)^{m}\right]
$$

Where $\bar{\sigma}=$ equivalent stress, $\bar{\varepsilon}=$ equivalent plastic strain, $\dot{\bar{\varepsilon}}=$ equivalent plastic strain rate, $\dot{\bar{\varepsilon}} o=$ initial reference plastic strain rate, $\mathrm{T}=$ operating temperature, $T_{o}=$ room temperature, $T_{m}=$ the melting temperature, $A=$ initial yield stress, $B=$ strain hardening coefficient, $n=$ strain hardening index, $C=$ strain rate dependency coefficient, and $m=$ thermal softening index.

Tool wear calculation with Usui model as shown in eq (2):

$$
w=\int a p V^{\left(-\frac{b}{T}\right)} d t
$$

Where $p=$ interface pressure, $V=$ sliding velocity, $T=$ interface temperature (in degrees absolute), $d t=$ time increment, $a, b=$ experimentally calibrated coefficients.

Table 5. Boundary conditions.

\begin{tabular}{llll}
\hline $\begin{array}{l}\text { Shear friction } \\
\text { coeff. }\end{array}$ & $\begin{array}{l}\text { Interface heat } \\
\text { transfer coeff. }\end{array}$ & Convection coeff. & $\begin{array}{l}\text { Environment } \\
\text { temperature }\end{array}$ \\
\hline 0.5 & $100\left(\mathrm{~N} / \mathrm{smm}^{\circ} \mathrm{C}\right)$ & 0.02 & $20^{\circ} \mathrm{C}$ \\
\hline
\end{tabular}

The tool is meshed with 45.000 tetrahedron elements, while the number of elements in the workpiece is kept at $20 \%$ of feed rate. Simulation steps are 16000 and data are saved every 25 steps.

\section{Taguchi Method}

The Taguchi method is a powerful tool to design optimization for quality. This method uses a special design of orthogonal array (OA) to study the quality characteristics with a minimal number of experiments [5], and signal-tonoise ratios $(\mathrm{S} / \mathrm{N})$ are used to evaluate the performance characteristics. 
Minimum experiments $=1+(\#$ factors $\mathrm{x}(\#$ levels -1$))$

For Taguchi method, there are 3 types of the signal-tonoise ratio.

$$
\begin{aligned}
& \text { Smaller-is-the-better: } S / N=-10 \log \left(\frac{1}{n} \sum_{i=1}^{n} y_{i}^{2}\right) \\
& \text { Larger-is-the-better: } S / N=-10 \log \left(\frac{1}{n} \sum_{i=1}^{n} \frac{1}{y_{i}^{2}}\right) \\
& \text { Nominal-is-the-best: } S / N=10 \log \left(\frac{\bar{y}}{s_{y}^{2}}\right)
\end{aligned}
$$

The Taguchi method applied in this study, the input parameters includes 3 factors: back rake angle (BR), side rake angle (SR) and side cutting-edge angle (SCEA) with 4 levels.

Minimum experiments $=1+[(\mathrm{L}-1) \mathrm{P}]=1+[(4-1) 3]=10 \approx \mathrm{L} 16$.

And the output parameters of the simulation analysis are cutting forces, temperature and tool wear, so we will select the first criterion (smaller is the better).

Table 6. The L16 inner orthogonal array.

\begin{tabular}{llll}
\hline Trial no & Side cutting- edge angle $\left(\right.$ SCEA) $\left(^{\circ}\right)$ & Back rake angle $\left(\right.$ BR) $\left(^{\circ}\right)$ & Side rake angle $\left(\right.$ SR) $\left({ }^{\circ}\right)$ \\
\hline 1 & 0 & -5 & -5 \\
2 & 0 & -7 & -7 \\
3 & 0 & -9 & -9 \\
4 & 0 & -11 & -11 \\
5 & 15 & -5 & -7 \\
6 & 15 & -7 & -5 \\
7 & 15 & -9 & -11 \\
8 & 15 & -11 & -9 \\
9 & 30 & -5 & -9 \\
10 & 30 & -7 & -11 \\
11 & 30 & -9 & -5 \\
12 & 30 & -11 & -7 \\
13 & 45 & -5 & -11 \\
14 & 45 & -7 & -9 \\
15 & 45 & -9 & -7 \\
16 & 45 & -11 & -5 \\
\hline
\end{tabular}

This setup allows the testing of all 3 factors with 4 levels without having to run $64\left(=4^{3}\right)$

\section{Simulation Results and Discussion}

\subsection{Numerical Results}

Based on the L16 inner orthogonal array, finite element analysis (FEA) is conducted to investigate effects of tool geometry

\begin{tabular}{|c|c|c|c|c|c|c|}
\hline \multirow[t]{2}{*}{ Trial no } & \multirow[t]{2}{*}{ Tool-chip interface temp $\left({ }^{\circ} \mathrm{C}\right)$} & \multirow[t]{2}{*}{ Wear depth (mm) } & \multicolumn{4}{|c|}{ Cutting forces (N) } \\
\hline & & & $\mathbf{F x}$ & Fy & $\mathbf{F z}$ & F resultant \\
\hline 1 & 682 & $1.15 \mathrm{E}-7$ & 173 & 960 & 168 & 989 \\
\hline 2 & 690 & $1.19 \mathrm{E}-7$ & 209 & 971 & 206 & 1014 \\
\hline 3 & 737 & $1.46 \mathrm{E}-7$ & 314 & 1304 & 314 & 1377 \\
\hline 4 & 772 & $1.23 \mathrm{E}-7$ & 364 & 1302 & 389 & 1406 \\
\hline 5 & 686 & $1.18 \mathrm{E}-7$ & 209 & 1049 & 233 & 1094 \\
\hline 6 & 695 & $1.34 \mathrm{E}-7$ & 184 & 1104 & 271 & 1151 \\
\hline 8 & 720 & $1.35 \mathrm{E}-7$ & 288 & 1192 & 409 & 1292 \\
\hline 9 & 679 & $1.11 \mathrm{E}-7$ & 171 & 802 & 218 & 848 \\
\hline 10 & 700 & $1.24 \mathrm{E}-7$ & 224 & 954 & 339 & 1036 \\
\hline 11 & 674 & $1.13 \mathrm{E}-7$ & 127 & 792 & 236 & 836 \\
\hline 12 & 696 & $1.13 \mathrm{E}-7$ & 159 & 826 & 295 & 891 \\
\hline 13 & 679 & $0.93 \mathrm{E}-7$ & 150 & 751 & 254 & 806 \\
\hline 14 & 694 & $1.07 \mathrm{E}-7$ & 139 & 832 & 297 & 894 \\
\hline 16 & 683 & $0.95 \mathrm{E}-7$ & 101 & 745 & 268 & 798 \\
\hline
\end{tabular}
parameters: SCEA, BR and SR on cutting forces, temperature and tool wear in turning. The results are shown in Table 7.

Table 7. The output quality characteristics of simulation analysis.

Based on the results in Table 7 , when the side rake angle and the back rake angle decrease from $-5^{\circ}$ to $-11^{\circ}$, the temperature on the tool-chip interface and the cutting force increase from $682^{\circ} \mathrm{C}$ to $772^{\circ} \mathrm{C}$ and from $989 \mathrm{~N}$ to $1406 \mathrm{~N}$, respectively. This is fully agreeable with theory and the previous studies by Stephenson et al. [6], Gunay et al. [7], 
Haci Saglam et al. [8], Cerenitti [9] and Sabri [10]. Because the rake angles decrease, it causes more the contact area and friction between the rake face and the chip as well as the chips flow more difficult across the rake face (chip jamming) as the rake angles decrease, then it causes more the temperature at the tool-chip interface during cutting process and the cutting force is bigger.

Using Minitab software to analysis the results from the simulation, showed in Table 8 and Fig. 3.

Table 8 . The combined S/N ratio of the output quality characteristics.

\begin{tabular}{|c|c|c|c|c|c|c|c|}
\hline \multirow[t]{2}{*}{ Trial no } & \multirow[t]{2}{*}{ Tool-chip interface temp $\left({ }^{\circ} \mathrm{C}\right)$} & \multirow[t]{2}{*}{ Wear depth (mm) } & \multicolumn{4}{|c|}{ Cutting forces (N) } & \multirow[t]{2}{*}{ Combined $\mathrm{S} / \mathrm{N}$ ratio } \\
\hline & & & $\mathbf{F x}$ & Fy & $\mathbf{F z}$ & F resultant & \\
\hline 1 & 682 & $1.15 \mathrm{E}-7$ & 173 & 960 & 168 & 989 & -56.7731 \\
\hline 2 & 690 & $1.19 \mathrm{E}-7$ & 209 & 971 & 206 & 1014 & -56.9624 \\
\hline 3 & 737 & $1.46 \mathrm{E}-7$ & 314 & 1304 & 314 & 1377 & -59.1014 \\
\hline 4 & 772 & $1.23 \mathrm{E}-7$ & 364 & 1302 & 389 & 1406 & -59.3329 \\
\hline 5 & 686 & $1.18 \mathrm{E}-7$ & 209 & 1049 & 233 & 1094 & -57.4493 \\
\hline 6 & 695 & $1.34 \mathrm{E}-7$ & 184 & 1104 & 271 & 1151 & -57.8004 \\
\hline 7 & 729 & $1.35 \mathrm{E}-7$ & 329 & 1217 & 390 & 1319 & -58.7913 \\
\hline 8 & 720 & $1.35 \mathrm{E}-7$ & 288 & 1192 & 409 & 1292 & -58.6286 \\
\hline 9 & 679 & $1.11 \mathrm{E}-7$ & 171 & 802 & 218 & 848 & -55.9481 \\
\hline 10 & 700 & $1.24 \mathrm{E}-7$ & 224 & 954 & 339 & 1036 & -57.1692 \\
\hline 11 & 674 & $1.13 \mathrm{E}-7$ & 127 & 792 & 236 & 836 & -55.8477 \\
\hline 12 & 696 & $1.13 \mathrm{E}-7$ & 159 & 826 & 295 & 891 & -56.2951 \\
\hline 13 & 679 & $0.93 \mathrm{E}-7$ & 150 & 751 & 254 & 806 & -55.6847 \\
\hline 14 & 694 & $1.07 \mathrm{E}-7$ & 139 & 832 & 297 & 894 & -56.3038 \\
\hline 15 & 685 & $0.96 \mathrm{E}-7$ & 120 & 796 & 273 & 824 & -55.8186 \\
\hline 16 & 683 & $0.95 \mathrm{E}-7$ & 101 & 745 & 268 & 798 & -55.6557 \\
\hline
\end{tabular}

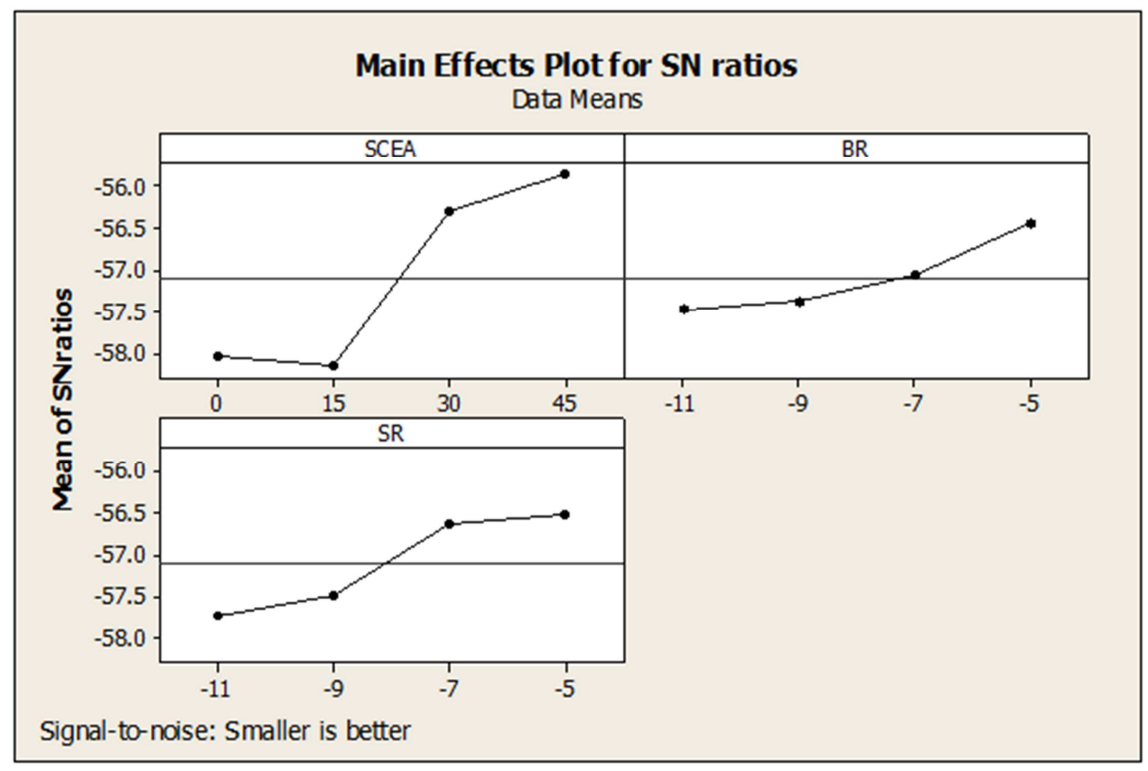

Fig. 3. Main effects plot for $S / N$ ratios.

From Table 8 and Fig. 3, the optimum tool geometry parameters are $\mathrm{SCEA}=45^{\circ}, \mathrm{BR}=-5^{\circ}$ and $\mathrm{SR}=-5^{\circ}$.

Furthermore, an analysis of variance (ANOVA) is performed to see which process parameters are significant [11]. The ANOVA is given in Table 9.

Table 9. ANOVA for $S / N$ ratio.

\begin{tabular}{|c|c|c|c|c|c|c|c|}
\hline Source & DF & Seq SS & Adj SS & Adj MS & $\mathbf{F}$ & $\mathbf{P}$ & $\%$ Contribution \\
\hline SCEA & 3 & 16.6686 & 16.6686 & 5.5562 & 29.70 & 0.001 & 67.11 \\
\hline BR & 3 & 2.5333 & 2.5333 & 0.8444 & 4.51 & 0.056 & 10.20 \\
\hline SR & 3 & 4.5150 & 4.5150 & 1.5050 & 8.04 & 0.016 & 18.18 \\
\hline Residual error & 6 & 1.1226 & 1.1226 & 0.1871 & & & \\
\hline Total & 15 & 24.8396 & & & & & \\
\hline
\end{tabular}


From the ANOVA: SCEA has the largest effect on the output quality characteristics with $67.11 \%$, SR with $18.18 \%$ and BR has the smallest effect on the output quality characteristics with $10.20 \%$.

With the identified optimum tool geometry parameters, a validation simulation analysis is performed.

Table 10. The output quality characteristics of simulation analysis with the identified optimum tool geometry parameter.

\begin{tabular}{llllllll}
\hline Trial no & Tool-chip interface temp $\left({ }^{\circ} \mathbf{C}\right)$ & Wear depth $(\mathbf{m m})$ & \multicolumn{2}{l}{ Cutting forces $(\mathbf{N})$} & & \\
\hline & & & Fx & Fy & Fz & F resultant \\
\hline 1 & 655 & $0.86 \mathrm{E}-7$ & 86 & 696 & 176 & 723 \\
\hline
\end{tabular}

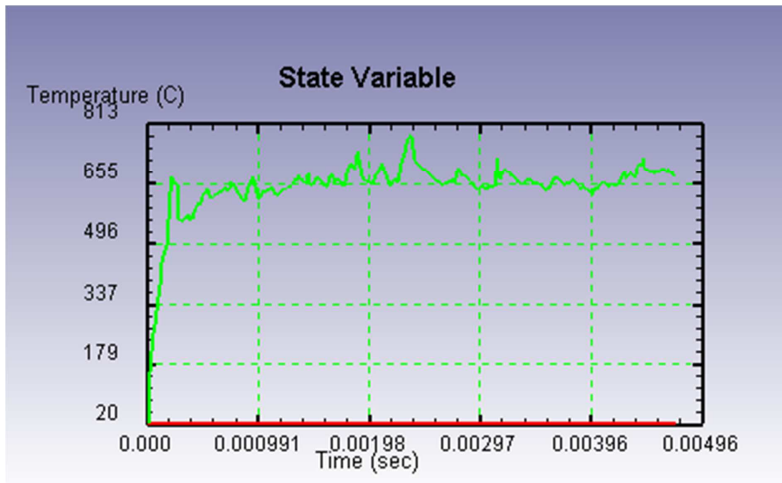

Fig. 4. The generated temperature in machining process.

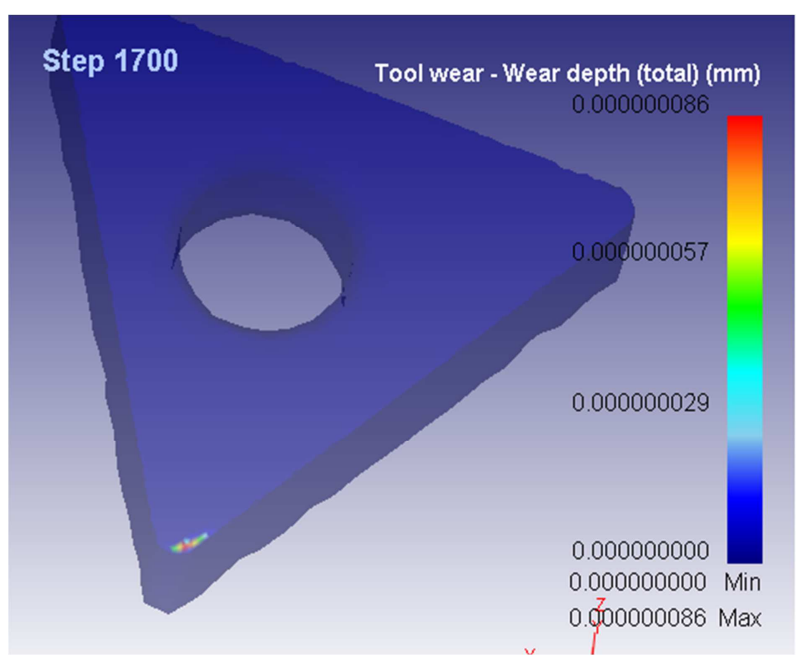

Fig. 5. The wear of tool in machining process.

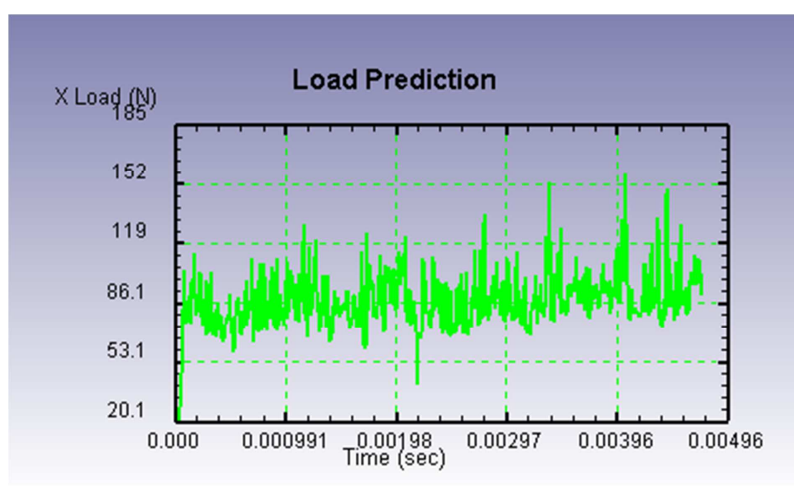

a. Feed force

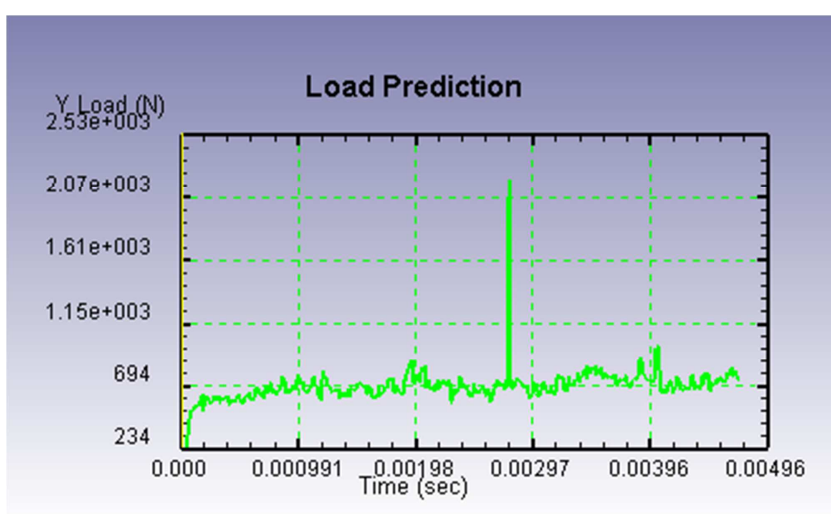

b. Main cutting force

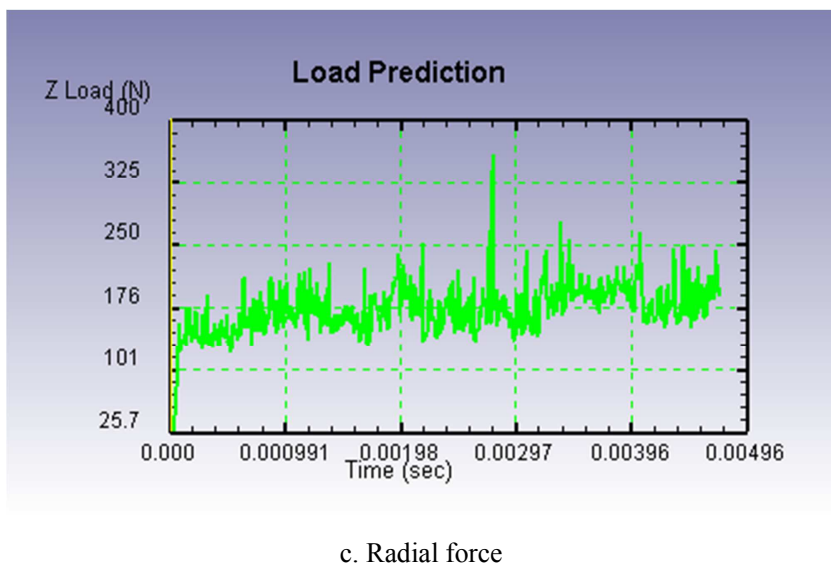

Fig. 6. The generated cutting forces during the cutting simulation analysis.

\subsection{Comparison Between Experimental and Numerical Results}

The simulation result obtained were validated by comparison with appropriate tool-work thermocouple measurements provided in Ref [12]. The cutting process simulation parameters were taken same conditions used in the reference experiment, i.e. cutting speeds of 103.2, 206.4 and $330 \mathrm{~m} / \mathrm{min}$, feed rate of $0.16 \mathrm{~mm} / \mathrm{rev}$, depth of cut of $2 \mathrm{~mm}$, AISI 1045 steel workpiece and tungsten carbide tool material as well as the tool's geometrical features. The comparison between measured and computed values of the average toolchip interface temperature is presented in Fig. 7 [13]. 


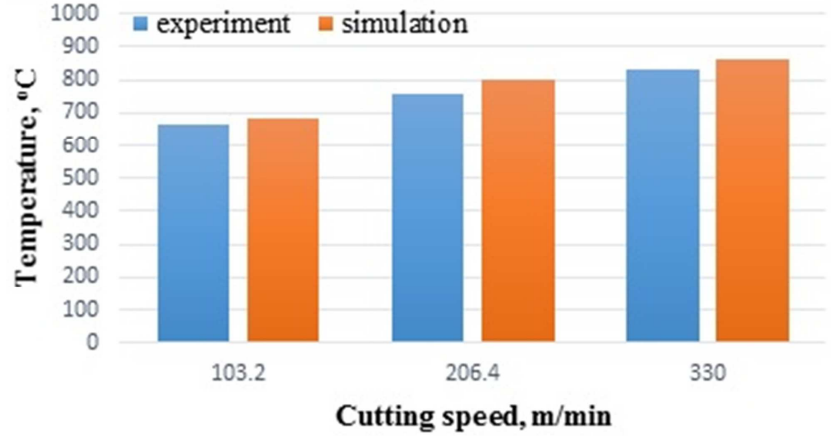

Fig. 7. Comparison between measured and computed tool-chip interface temperatures.

It shows good agreement between experimental and simulation values for the three selected cutting speeds with the percentage error of $2.3,5.3$, and $3.6 \%$ for speeds 103.2 , 206.4 , and $330 \mathrm{~m} / \mathrm{min}$ respectively.

\section{Conclusion}

From the simulation results, it is concluded that:

When the side rake and back rake angles decrease from $-5^{\circ}$ to $-11^{\circ}$, the temperature in the machining process and the cutting force increase from $682^{\circ} \mathrm{C}$ to $772^{\circ} \mathrm{C}$ and from $989 \mathrm{~N}$ to $1406 \mathrm{~N}$, respectively.

The identified optimum tool geometry parameters are $\mathrm{SCEA}=45^{\circ}, \mathrm{BR}=-5^{\circ}$ and $\mathrm{SR}=-5^{\circ}$. The SCEA has the largest effect on the output quality characteristics with $67.11 \%$, SR with $18.18 \%$ and BR has the smallest effect on the output quality characteristics with $10.20 \%$.

All of the results are agreeable with theory and some simulations and experiments in references.

\section{References}

[1] Hassan Abdel, Gawad El-Hofy. Fundamentals of machining processes: conventional and nonconventional processes. CRC press, 2006.

[2] Valery Marinov. Manufacturing processes for metal products. Kendall Hunt Publishing Company, 2010.

[3] T. Ozel, I. Llanos, J. Soriano And P. J. Arrazola. 3D finite element modelling of chip formation process for machining inconel 718: comparison of fe software predictions. Machining Science and Technology. 15, (2011), 21-46.
[4] Tugrul O" zel. The influence of friction models on finite element simulations of machining. International Journal of Machine Tools \& Manufacture, 46 (2006) 518-530.

[5] N. Senthilkumar, T. Tamizharasan. Effect of tool geometry in turning aisi 1045 steel: experimental investigation and fem analysis. Arab J Sci Eng (2014) 39, 4963-4975.

[6] Stephenson, A. A., \& Agapiou, J. S. Metal cutting theory and practice. Marcel Dekker. Inc, New York, 1996.

[7] Gunay, M., Korkut, I. \& Seker, U. Experimental investigation of the effect of cutting tool rake angle on main cutting force. Journal of Material Processing Technology, 166, 2005, 44-49.

[8] Haci Saglam, Faruk Unsacar, Suleyman Yaldiz. Investigation of the effect of rake angle and approaching angle on main cutting force and tool tip temperature. International Journal of Machine Tools \& Manufacture, 46 (2006), 132-141.

[9] Cerenitti, E., Fallbohmer, P. \& Altan, T. Application of $2 \mathrm{~d}$ fem to chip formation in orthogonal cutting. Journal of Materials Processing Technology, 59, 1996, 169-180.

[10] Sabri Ozturk. Slip-line metal cutting model with negative rake angle, Journal of the Brazilian Society of Mechanical Sciences and Engineering, vol.34 (2012).

[11] W. H. Yang, Y. S. Tarng. Design optimization of cutting parameters for turning operations based on the Taguchi method. Journal of Material Processing Technology, 84(1998) 122-129.

[12] W. Grzesik, P. Nies ${ }^{3}$ ony. FEM-based thermal modelling of the cutting process using power law temperature dependent concept. International Scientific Journal, Volume 29 Issue 2February 2008, 105-108.

[13] W. Grzesik, M. Bartoszuk, P. Nieslony. Finite element modelling of temperature distribution in the cutting zone in turning processes with differently coated tools. Journal of Materials Processing Technology 164-165 (2005), 12041211.

[14] Corina Constantin, Sorin Mihai Croitoru, George Constantin, Claudiu Florinel Bisu. 3D fem analysis of cutting processes. Advances In Visualization, Imaging And Simulation.

[15] Shufeng Sun1,A, Pingping Wang1,B, Xin Wu1,C, Sen Lin1,D. $\mathrm{NC}$ turning process parameters optimization based on simulation software. Applied Mechanics And Materials Vols. 271-272 (2013), 452-456.

[16] Ruan Hongyan1, A, Yan Hua1, Lu Shubin1, Liu Huixia1, Wang Xiao1. The investigation of tool wear in metal machiningusing finite element method. Key Engineering Materials Vols 407-408 (2009), 395-399. 